\section{Como os países ricos ficaram ricos ... e por que os países pobres continuam pobres}

REINERT, Erik S. Como os países ricos ficaram ricos ...e por que os países pobres continuam pobres. Rio de Janeiro: Contraponto; Centro Internacional Celso Furtado de Políticas para o Desenvolvimento, 2016.

\section{Jorgemar Soares Felix*}

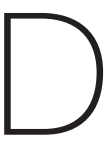
epois de quase uma década de crise mundial, o Fundo Monetário Internacional (FMI) tem feito um esforço para posicionar a questão da desigualdade social no centro dos objetivos das políticas macroeconômicas dos países. Essa atitude veio a público a partir de um artigo, muito comentado no debate acadêmico, publicado em junho de 2016, na revista do próprio FMI, e assinado pelos economistas Jonathan D. Ostry, Prakash Loungani e Davide Fuceri (2016), sob o título "Neoliberalism: oversold?" (Neoliberalismo: exagerado?). Esse texto foi percebido como uma espécie mea culpa do FMI sobre seu receituário econômico a partir dos anos 1980 direcionado, principalmente, para a América Latina - o chamado "Consenso de Washington"1.

Esse rol de medidas, como se sabe, incriminou certas práticas de gestão da macroeconomia e recomendou um elenco de outras para garantir o desenvolvimento econômico, com a promessa de que esse seria o caminho para o desenvolvimento (e o enriquecimento) desses países. Se adotassem aquele conjunto de reformas - defendia então o FMI - ocorreria o catching up (ou alcançamento) em relação aos países ricos. Quase 30 anos depois, segundo os autores do texto, o que se verificou foi que o crescimento econômico desse período, de forma alguma, significou aumento do bem-estar da população. Pelo contrário, ampliou a desigualdade social e colocou em risco a expansão econômica estável. Em outras palavras, o crescimento não se constituiu em desenvolvimento. O caso citado pelos autores é o do Chile, seguidor mais fiel e apaixonado desse receituário durante a ditadura de Pinochet, entre os anos 1973 e 1990 (ver Felix, 2016).

Outras publicações do FMI têm dado, atualmente, mais destaque para críticas às políticas neoliberais e seu completo desprezo pelo objetivo da igualdade social. No entanto, um fato ocorrido em janeiro de 2017, no famoso Fórum de Davos, foi mais
* Jorgemar Soares Felix é professor convidado do mestrado (stricto sensu) em gerontologia na Universidade de São Paulo $(\mathrm{EACH})$, professor de economia da Fundação Escola de Sociologia e Política de São Paulo, doutorando em ciências sociais pela Pontifícia Universidade Católica de São Paulo (PUC$\mathrm{SP})$, mestre em economia política (PUC-SP), São Paulo, São Paulo, Brasil. <jorgemarfelix@ gmail.com>.

1. Assim foi denominado o documento formulado por economistas de instituições financeiras sediadas na capital federal estadunidense, como o FMI, o Banco Mundial e próprio Departamento do Tesouro dos Estados Unidos. Foi redigido e resumido pelo economista John Williamson com as regras que deveriam orientar a economia 
dos países a partir de 1989. No ano seguinte, tornou-se documento oficial do FMI. Essa "receita única" para todos os países da América Latina alcançarem o equilíbrio macroeconômico previa austeridade fiscal, redução da carga tributária, câmbio flutuante, "juros de mercado", abertura comercial, eliminação de restrições ao investimento estrangeiro direto, desregulamentação financeira, direito à propriedade intelectual (patentes) e privatização das estatais e dos sistemas de previdência social.

\section{Diante de} Meirelles, a diretora do FMI afirma que a prioridade deve ser o combate à desigualdade (Lagarde, 2017). significante para ilustrar essa tentativa de mudança de paradigma do FMI, assim como sua absoluta falta de sucesso em empreendê-la. Naquele fórum, a diretora-geral do FMI, Christine Lagarde $(2017)^{2}$, rebateu o discurso do ministro brasileiro da Fazenda, Henrique Meirelles, sobre a necessidade de reformas seguindo o receituário do Consenso de Washington, com a cobrança por maior preocupação com a desigualdade social. Foi solenemente ignorada. Segundo Meirelles, no estágio econômico atual, o que vale para os países ricos não vale para o Brasil. Nossa economia, na visão dele, precisa de mais abertura, mais reformas e menos Estado, ou seja, mais do que pregava o Consenso de Washington. O debate é apenas um pequeno exemplo do quão difícil é mudar os termos e argumentos das narrativas cristalizadas a partir de interesses sejam econômicos, históricos, pessoais em todos os tipos de relações socioeconômicas ou internacionais.

É neste ambiente que surge a tradução para o português do livro, já clássico, de Erik S. Reinert, Como os países ricos ficaram ricos ...e por que os países pobres continuam pobres, publicado em parceria da Editora Contraponto com o Centro Internacional Celso Furtado de Políticas para o Desenvolvimento. Aos 68 anos, Reinert notabilizou-se pelos estudos do desenvolvimento e da história econômica e é professor da Talling University of Technology, na Estônia, depois de inúmeros trabalhos para o Banco Mundial, dentre diversas outras instituições. Sua abordagem histórica do enriquecimento ou da pobreza crônica dos países oferece uma musculatura de argumentos e dados empíricos para ajudar aqueles interessados em responder à recorrente questão da economia mundial: Por que alguns países enriqueceram e outros estão condenados à pobreza? E também por que a desigualdade entre países e dentro dos países se tornou o "novo normal" do século XXI?

Antes de descrever as contribuições do autor e o livro, é importante destacar que Reinert é um crítico do neoliberalismo sem se filiar a nenhum de seus opostos extremos, como o marxismo ou o keynesianismo clássico. Seu posicionamento é eclético e com grande inclinação ao schumpterianismo. É a partir daí que Reinert acusa a "visão de mundo dos economistas", justamente por terem estabelecido essa "nova normalidade" da pobreza e da desigualdade entre os países. Diz ele que, tradicionalmente, riqueza e pobreza eram explicadas reconhecendo-se que diferentes atividades econômicas eram qualitativamente distintas como portadoras de riqueza, mas esta perspectiva se perdeu na teoria dominante nos nossos dias ou na economia do "manual-padrão", como ele prefere.

Ele começa, então, explicando as diferenças entre as atividades econômicas que predominam nos países ricos e as que predominam nos países pobres: concorrência 
"imperfeita" e "perfeita", de um lado, e rendimentos "crescentes" e "decrescentes", de outro. Nos países pobres, como se sabe, com economias baseadas em commodities com dominância de concorrência perfeita, o produtor não poderá jamais influenciar o preço dos artigos que produz. O esforço da economia do "manual-padrão", portanto, é enclausurar os países pobres na utopia da "concorrência perfeita e dos rendimentos decrescentes". Em outras palavras, impedir que esses países se industrializem num estágio de sofisticação que os tornem aptos a ingressar na "concorrência imperfeita" que prevalece, sempre segundo sua tese, no comércio mundial entre os países com atividades de "rendimentos crescentes".

Paradoxalmente, essa lógica determina, na visão de Reinert, que "a chave" para se tornar rico é o país ser pobre em recursos naturais (p. 48). Neste ponto, a interpretação do autor guarda uma interseç̧ão com a teoria novo-desenvolvimentista de Luiz Carlos Bresser-Pereira, José Luís Oreiro e Nelson Marconi (2016: 67), que confere importância crucial à neutralização da doença holandesa. Se os recursos naturais são escassos, o país empreende na indústria e, como concordam marxistas e liberais, "o que cria nações ricas são a industrialização e a mudança tecnológica" (p. 49). Segundo Reinert, a melhor política industrial surge quando marxistas e schumpeterianos se unem ao longo do mesmo eixo político.

É a história, no entanto, no entender do autor, que revela como os países ricos tornaram-se ricos usando métodos que hoje estão proibidos pelas "condicionalidades" do Consenso de Washington. Antes disso, porém, é obviamente necessário dar ênfase às heranças da escravidão "que bloqueiam o desenvolvimento econômico até hoje". Mas não é esse o ponto principal de Reinert. Ele contribui para o debate com uma visão bastante singular a partir da criação de categorias explicativas. A primeira delas é a "emulação" ou a imitação positiva que países, como os Estados Unidos, adotaram como prática no século XIX para fazer o "alcançamento" do Reino Unido.

Emulação, lembra Reinert, é, segundo o Dicionário Oxford, o "esforço para se igualar ou ultrapassar outros em qualquer feito ou qualidade; também o desejo ou a ambição de igualar ou exceder". Em termos modernos, emulação seria "empareIhamento" ou "salto à frente". Essa emulação, prossegue Reinert, foi sustentada por uma "caixa de ferramentas". Os países que se tornaram ricos nos séculos passados tinham essas ferramentas ao seu dispor ou conseguiram conquistá-las justamente negando a premissa de que o "que é bom para eles, não é bom para você". Pelo contrário, o empenho foi por uma emulação profunda. Segundo Reinert, o governo Eisenhower (1953-1961) rompeu com a teoria das vantagens comparativas ricardiana que determinava que os Estados Unidos deveriam ser produtores de alimentos 
e a Rússia de tecnologia e adotou as ferramentas necessárias para a emulação ao criar a Nasa, em 1958.

"Rivalidade, guerra e emulação criaram na Europa um sistema dinâmico de concorrência imperfeita e rendimentos crescentes" ao longo dos séculos, diz Reinert.

"Mercados perfeitos são para os pobres" (p. 60). Quanto mais pobre o país, tanto menos os ventos do laissez-faire sopram na direção certa. A crítica de Reinert é que a economia do "manual-padrão" ignorou sempre o contexto - algo como o que agora Lagarde tenta convencer Meirelles - e isso foi um "defeito fatal, que impediu qualquer grau de compreensão qualitativa" (p. 61). Em seu entendimento, a teoria das vantagens comparativas de David Ricardo (1772-1823), que sustenta o comércio mundial e o neoliberalismo, tornou possível que uma nação "se especializ[asse] em ser pobre", pois, o Consenso de Washington proíbe a esses países a utilização da mesma "caixa de ferramentas" usada no passado pelos países ricos.

A interpretação de Reinert, como se vê, é ressonante com o famoso livro de Ha-Joon Chang (2004), Chutando a escada. A estratégia do desenvolvimento em perspectiva histórica, embora seu caminho teórico e sua construção histórica sejam bem distintos. Essas ferramentas consistiram em subsídios, tarifas de exportação de matérias primas e protecionismo. Os Estados Unidos, lembra Reinert, protegeram sua indústria manufatureira durante cerca de 150 anos. Essas ferramentas, diz o autor, tornam o livre-comércio mundial uma quimera (p. 67).

O que determinou, sempre segundo Reinert, a riqueza das nações desenvolvidas e industrializadas foi a tradição teórica do que ele chama de "outro cânone" da economia. Esse "outro cânone", seguindo Alfred Marshall (1842-1924), exige que as analogias ou as premissas baseadas na física, adotadas pela economia neoclássica, sejam abandonadas e trocadas pela biologia, com muito mais complexidade. Ele leva em conta a informação assimétrica, o tempo, a história, o espaço e o conhecimento a partir da realidade e nunca de modelos matemáticos abstratos.

A trajetória de exposição no livro se dá em oito capítulos, além de seis apêndices e de um posfácio especial para a edição brasileira. No primeiro capítulo, o autor expõe os diferentes tipos de teorias econômicas; no segundo, continua com a evolução das duas abordagens distintas; no terceiro, desenvolve o conceito da emulação desde a Inglaterra de Henrique VII, no século XV, quando os países adotam essa estratégia. No quarto capítulo, Reinert aborda a globalização e explora a "sinergia" no campo da educação, a evasão de cérebros dos países pobres, a dificuldade para os países pobres investirem em pesquisa e desenvolvimento. Ele também tenta explicar o crescimento de China, Índia e Coréia do Sul, e sustenta que, esses países 
fizeram exatamente o contrário do que determinava o Consenso de Washington para a América Latina (p. 173).

Reinert ainda reflete sobre o atual estágio tecnológico que define como "mudança de paradigma tecnoeconômico" e aponta os novos desafios para as nações pobres e as oportunidades de estas mudarem as relações de poder no planeta. No quinto capítulo, o autor mostra como se dá o processo de "primitivização", ou seja, como os países pobres ficam ainda mais pobres com a insistência em seguir o "manual-padrão". Fracassos e mitos do "fim da história" são analisados no sexto capítulo, além de criticar dez argumentos do Consenso de Washington, que são um a um listados e esmiuçados expondo suas contradições. No sétimo capítulo, Reinert mostra como as soluções apontadas pelos organismos multilaterais se constituem, como ele define, de "economia paliativa" em relação à pobreza a partir de uma visão crítica dos objetivos do milênio, da Organização das Nações Unidas. Em outras palavras, os objetivos têm apenas a missão de atenuar a pobreza. Seu exemplo é tragicômico: enquanto na Europa se erradicou a malária, na África a solução é distribuir mosquiteiros. Reinert encerra o livro com a análise da dificuldade de a economia contemporânea permitir a criação de países de renda média, tema do oitavo e último capítulo.

O livro de Reinert merece atenção especial dos cientistas sociais, incluindo os economistas. A grande riqueza de fatos históricos e dados estatísticos, assim como categorias analíticas, fortalece o argumento de que a pobreza perene, seja de indivíduos ou de países no século XXI, é um fenômeno independente ou descolado do determinismo econômico e muito mais uma consequência do jogo disputado, por séculos, entre vários atores sociais no processo historicamente conhecido como globalização. Os locutores da economia do "manual padrão" sempre preferem transmitir esse jogo repleto de expressões tecnicistas e justificativas pseudocientíficas, mas Reinert demonstra que esses argumentos são contaminados por um elevado grau de ideologia e de interesses do capitalismo global.

\section{Referências}

BRESSER-PEREIRA, Luiz Carlos; OREIRO, José Luís; MARCONI, Nelson. Macroeconomia desenvolvimentista, teoria e política econômica do novo desenvolvimentismo. São Paulo: Elsevier, 2016.

CHANG, Ha-Joon. Chutando a escada. A estratégia do desenvolvimento em perspectiva histórica. São Paulo: Editora Unesp, 2004. 
FELIX, Jorgemar Soares. A previdência do Chile e o "exagero do neoliberalismo". Revista Brasileiros (blog), 2016. Disponível em: <http://brasileiros.com.br/2016/06/ previdencia-chile-e-o-exagero-neoliberalismo/>. Acesso em: 26 Mar. 2017.

LAGARDE, Christine. Discurso em Davos. BBC Brasil, 18 Jan. 2017. Disponível em: <http://www.bbc.com/portuguese/brasil-38670576>. Acesso em: 26 Mar. 2017.

OSTRY, Jonathan D.; LOUNGANI, Prakash; FUCERI, Davide. Neoliberalism: oversold? Finance \& Development, p. 38-41, Jun. 2016. 